Climate change

\section{Tropical flip-flop connections}

\author{
John C. H. Chiang and Athanasios Koutavas
}

A long climatic record shows that episodic wet periods in northeastern Brazil are linked to distant climate anomalies. The ocean-atmosphere system can evidently undergo rapid and global reorganization.

very few years, the semi-arid but densely populated region of northeastern Brazil experiences severe drought. In 1997-98, exacerbated by poor distribution of resources, such an event caused great hardship. And in the catastrophic drought of 1877-79, hundreds of thousands of people perished. The causes of these conditions are neither accidental nor local, but part of an orchestrated sequence of large-scale atmospheric and oceanic processes over the entire tropical Atlantic (Fig. 1). These processes lead to changes in the seasonal southward migration of the Intertropical Convergence Zone (ITCZ) ${ }^{1}$, the rainfall band that spans the Atlantic. When the southward migration of the ITCZ in February-May stops short of northeastern Brazil, the rainy season fails.

For those seeking knowledge of past climate changes, however, northeastern Brazil presents an opportunity: what better place to focus on than one where flipflopping climate is singularly representative of changes throughout the entire tropical
Atlantic? Wang et al. (page 740 of this issue) $)^{2}$ have done just that. They find that over the past 210,000 years northeastern Brazil underwent episodic changes from its usual semi-arid state to a wetter climate, implying a persistently southward-shifted ITCZ. Unlike the present-day disturbances, which last a few years at most, these past wet episodes typically persisted for several centuries. The authors deduced the presence and duration of the wet periods from the growth patterns and ages of mineral deposits, called speleothems and travertines, in the northern part of Bahia state in Brazil.

Speleothems are deposited in caves, and travertines along spring-fed rivers and streams, when calcium carbonate precipitates out of supersaturated ground and spring waters; deposition is a good indicator of abundant rainfall. Northeastern Brazil is usually too arid to support the formation of either type of deposit (as is the case for present-day conditions), but repeated episodes of persistently wetter conditions evidently allowed them to form in the past.
The remains of vegetation embedded in the travertines show that semi-deciduous forest abounded during the wet phases, linking the Amazon rainforest in the northwest with the Atlantic rainforest along the eastern coast of Brazil. An intriguing idea put forward by Wang et al. is that the unusual biodiversity of these rainforests can be attributed partly to the floristic exchange made possible by the recurring shifts to a wet climate.

The more remarkable aspect of this study, however, is identification of the apparent synchrony of wet periods in northeastern Brazil with climate changes near and far. The timing of the wet periods can be accurately determined using uranium-thorium dating, a system that relies on decay products of radioactive uranium-238. The ages of speleothems analysed by Wang et al. correlate remarkably well with the timing of climate changes in different parts of the Northern Hemisphere - specifically, with weakening of the East Asian summer monsoon; with cold periods over Greenland; and with episodes in the North Atlantic, known as Heinrich events, that are characterized by massive release of icebergs into the open ocean from continental glaciers. Closer to home, Wang and colleagues' results elegantly confirm earlier indications of a southwarddisplaced ITCZ deduced from mineralogical changes in sediments of the Cariaco Basin, off Venezuela ${ }^{3}$.

What do these records tell us about the climate system? Cold episodes over the

Plant biochemistry

\title{
Green catalytic converter
}

A key component of the Kyoto

Protocol - the international

agreement that aims to reduce

greenhouse-gas concentrations -

is the control of carbon emissions

into the atmosphere. This will

require industries to reclaim and

recycle the carbon dioxide they

currently discard. Elsewhere in this

issue (see Nature 432, 779-782;

2004), Jörg Schwender and

colleagues show that plants are way

ahead of us in this respect.

Oil is the major storage product in most seeds, but the standard biochemical route for its synthesis was thought to be quite wasteful.

Plants employ a variation of glycolysis, the metabolic pathway also used by animals, which breaks down glucose to produce energy. One of its end products is pyruvate, which can be converted to acetyl-

CoA, a precursor for fatty acids and oils. This reaction also produces $\mathrm{CO}_{2}$. For every two carbon atoms that are made into oil, at least one should be lost as gas.

Schwender et al. found that oil production in seeds of Brassica napus (oilseed rape or canola; shown here) was nowhere near as inefficient. Using radioactive labelling, they measured the ratio of carbon used to carbon lost as almost three to one. Closer investigation showed that these savings are achieved by a previously unsuspected function of probably the most abundant protein in the world, Rubisco.

Rubisco catalyses a critical reaction in photosynthesis. It combines $\mathrm{CO}_{2}$ with the sugar ribulose 1,5-bisphosphate to produce two molecules of phosphoglyceric acid as part of a complicated series of chemical reactions known as the Calvin cycle. It turns out that rape seeds have high levels of Rubisco, but no detectable Calvin-cycle activity. Instead, the enzyme's supply of

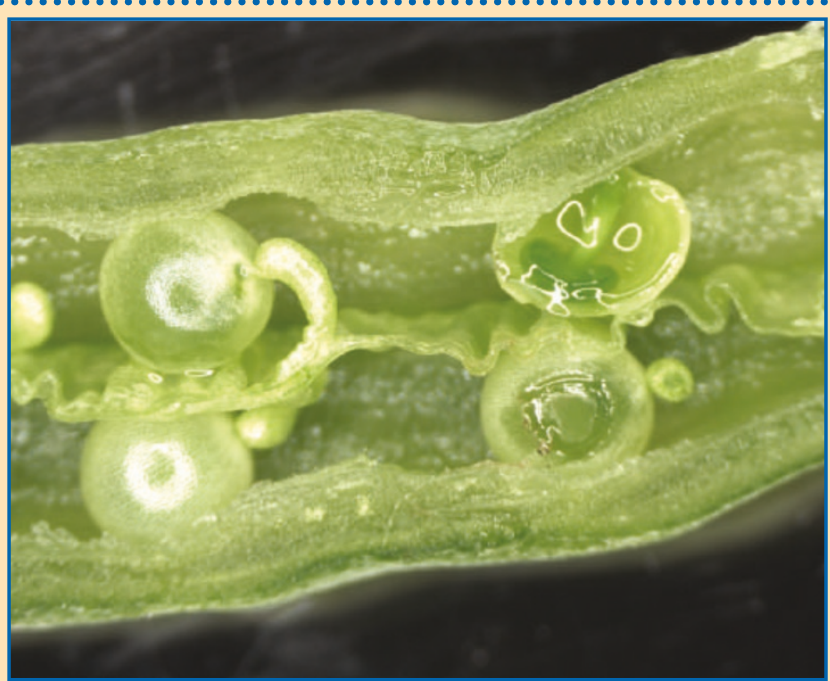

ribulose 1,5-bisphosphate is synthesized afresh from fructose and glyceraldehydes, allowing it to soak up the $\mathrm{CO}_{2}$ produced from making acetyl-CoA. The resulting pyruvate is then used to make more oil.

Not all seeds can reclaim $\mathrm{CO}_{2}$ in this way; sunflower seeds, for example, are much less efficient in their oil production. The difference is that growing Brassica seeds are green. Despite being enclosed in a pod, enough light filters through to be captured by the pigment chlorophyll, supplying the energy needed for the synthesis of ribulose. In seeds, at least, it is only the greens that recycle. Christopher Surridge 
North Atlantic during the last glacial period are thought to have arisen from abrupt variations in the Atlantic's thermohaline circulation $^{4}$, a density-driven circulation that carries warm and salty surface waters to the northern North Atlantic. As these waters release their heat to the atmosphere they become cold and dense, then sink, and return south as a deep current. A weakening or shutdown of this circulation - achieved by freshening the ocean surface waters from glacial meltwater or through other means reduces the heat transported to the North Atlantic and cools the climate there. These changes in thermohaline circulation are in essence high-latitude processes with no obvious link to the tropics; but recent discoveries have documented the presence of abrupt events in the northern tropical Atlantic, Pacific ${ }^{5}$ and Indian Ocean ${ }^{6}$ regions. And Wang et al. now establish their existence in the southern tropics with a dating accuracy that puts the synchrony with events in the North Atlantic, and in other tropical locations, beyond reasonable doubt.

This development significantly modifies our view of abrupt climate change. Shifts in the strength and distribution of atmospheric convection in the tropics dramatically affect the global climate by altering the global atmospheric circulation - analogous to how the El Niño-Southern Oscillation system in the tropical Pacific affects global climate today $^{7}$. The transport of water vapour will change as a result, possibly affecting the salinity and hence the density of the North Atlantic surface waters that determines the strength of the thermohaline circulation $^{8}$. Taken to the logical extreme, a competing 'tropical driver' hypothesis for abrupt climate changes could easily explain the observed global synchronization although, as yet, there is no convincing model for how such a driver might operate ${ }^{9}$.

It is nonetheless clear that a complete explanation of abrupt climate change must incorporate both the thermohaline circulation in the North Atlantic and climate processes that occur in the tropics. Results from simulations with climate models offer tantalizing clues as to how this might come about (see ref. 10 for an example). When the thermohaline circulation is forced to shut down, the models respond with rapid and widespread cooling of climate in the Northern Hemisphere and rearrangement of tropical rainfall. The Atlantic ITCZ seems to be particularly sensitive in this regard, and shifts in a manner consistent with the data of Wang and colleagues. Although it is still not clear how the global connections are set up, the tropical Atlantic may have a pivotal role in linking the high latitudes to the tropics ${ }^{11,12}$.

So, what lies ahead? We can hope for rapid progress in characterizing the timing and spatial extent of abrupt climate changes, particularly in the tropics and Southern

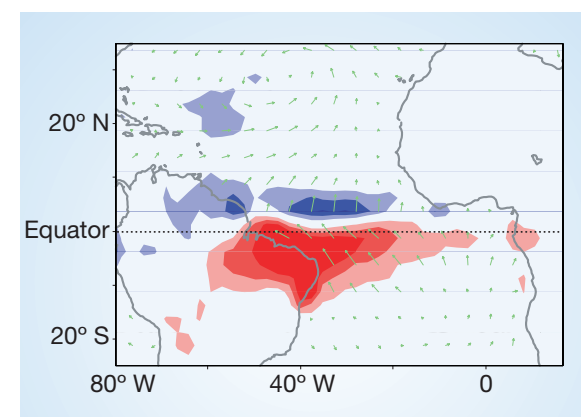

Figure 1 Determinants of present-day drought years in northeastern Brazil. An anomalous north-south gradient in ocean surface temperatures near the Equator (not shown), with warmer conditions in the north, drives a low-level atmospheric circulation, shown by arrows, that strengthens the trade winds in the southern Atlantic and weakens them in the north. The result is to impede the southward migration of the Atlantic Intertropical Convergence Zone, which increases rainfall in the northern tropical Atlantic (blue) and reduces it in the southern tropical Atlantic and northeastern Brazil (red). The opposite set of conditions, persisting over several centuries, is thought to characterize the wet episodes identified by Wang et al. ${ }^{2}$.

Hemisphere where data remain sparse. In this regard, the future looks bright for studies of speleothems, given the outstanding dating accuracy and time resolution that they offer. But speleothems are, of course, confined to land: marine records lack their advantages but remain essential.

For modelling, perhaps the key lesson offered by Wang et al. ${ }^{2}$ is a deeper appreciation of global interconnections in climate change. This view resonates with basic notions of how climate adjusts to forcings to maintain energy balance, necessitating changes to the Equator-to-pole temperature gradients and global transports of energy and moisture. But the palaeoclimate records are helping to provide an increasingly detailed view of how this system operates in the real world. Our knowledge of the dynamical adjustments to climate change and their sensitivities across models is still developing, and there is a substantial gap between model simulations and the intricacies of climate changes inferred from palaeodata. Bridging that gap is crucial to reaching the stage where we can make confident predictions about the consequences of our own, self-imposed climate change.

John C. H. Chiang is in the Department of Geography and Center for Atmospheric Sciences, 507 McCone Hall, University of California, Berkeley, California 94720-4740, USA.

e-mail:jchiang@atmos.berkeley.edu Athanasios Koutavas is at the Lamont-Doherty Earth Observatory of Columbia University,

Palisades, New York 10964, USA.

e-mail:athan@ldeo.columbia.edu

1. Hastenrath, S. \& Heller, L. Q. J. R. Meteorol. Soc. 103, 77-92 (1977).

2. Wang, X. et al. Nature 432, 740-743 (2004)

3. Peterson, L. C., Haug, G. H., Hughen, K. A. \& Röhl, U. Science 290, 1947-1951 (2000).

4. Rahmstorf, S. Nature 419, 207-214 (2002).

5. Stott, L., Poulsen, C., Lund, S. \& Thunell, R. Science 297, 222-226 (2002).

6. Burns, S. J., Fleitmann, D., Matter, A., Kramers, J. \& Al-Subbary, A. A. Science 301, 1365-1367 (2003).

7. Cane, M. A. Science 282, 59-61 (1998).

8. Schmittner, A., Appenzeller, C. \& Stocker, T. F. Geophys. Res. Lett. 27, 1163-1166 (2000)

9. Broecker, W. S. Science 300, 1519-1522 (2003).

10. Vellinga, M. \& Wood, R. A. Clim. Change 54, 251-267 (2002).

11. Chiang, J. C. H., Biasutti, M. \& Battisti, D. S. Paleoceanography 18, 10.1029/2003PA000916 (2003).

12. Dong, B. W. \& Sutton, R. T. Geophys. Res. Lett. 29, 10.1029/2002GL015229 (2002).

\section{Hearing}

\section{Channel at the hair's end}

\section{Jonathan Ashmore}

Ion channels controlled by sound underlie the sense of hearing. Having long eluded researchers, the first such mammalian channel has now been identified in the mouse inner ear.

W hen you hear a sound or shake your head, the hair cells of your inner ear convert movement into the electrical currency that the brain understands. But how such transduction from mechanical to electrical signals works on a molecular scale remains unclear. The problem is that the ear's hair cells are relatively few in number, and the molecules involved are sparse, so progress has been slow. On page 723 of this issue, however, Corey and colleagues ${ }^{1}$ suggest that a key component of the vertebrate 'mechano-transducer' is an ion channel called TRPA1.
Sound waves or head movements deflect rod-like projections called stereocilia on hair cells. These stereocilia stand out a few micrometres from the cell surface, and when they are rocked, their relative sliding motion pulls on a series of extracellular linking proteins that run between their tips - the 'tip links' (Fig. 1a, overleaf). The pulling makes ion channels in the stereocilia open, causing the hair cells to send signals to the brain. The identity and precise mechanism of action of these mechano-transducing channels remain obscure, however.

There have been hints from studies of 